\title{
Aquaporin 1 affects pregnancy outcome and regulates aquaporin 8 and 9 expressions in the placenta
}

\author{
Hui Luo ${ }^{1} \cdot$ Yi Liu $^{1} \cdot$ Yizuo Song $^{1} \cdot$ Ying Hua $^{1} \cdot$ Xueqiong Zhu ${ }^{1}$ (D) \\ Received: 5 February 2020 / Accepted: 24 April 2020 / Published online: 15 June 2020 \\ (C) The Author(s) 2020
}

\begin{abstract}
To explore the effects of aquaporin (AQP) 1 on pregnancy outcome and the association between expression of AQP1 and other AQPs in the placenta and foetal membranes, the rate of copulatory plugs and pregnancy, amniotic fluid (AF) volume, osmolality and composition were determined in $A Q P 1$-knockout $\left(A Q P 1^{-/-}\right)$mice at different gestational days (GD). The expression and location of AQP1 and other AQPs in the placenta and foetal membranes of $A Q P 1^{-/-}$mice, AQP1-siRNA transfected WISH cells and oligohydramnios patients were also detected. Compared to control mice, $A Q P 1^{-/}$mice exhibited reduced copulation plug and successful pregnancy rates, but these effects were accompanied by a larger AF volume and lower AF osmolality at late gestation. AQP9 expression was significantly decreased in the placenta and foetal membranes of $A Q P 1^{-/-}$mice, while AQP8 level was elevated in the foetal membranes of $A Q P 1^{-/-}$mice. Moreover, AQP9 expression was suppressed in WISH cells after AQP1 downregulation. Furthermore, AQP9 expression was associated with AQP1 level in the placenta and foetal membranes in oligohydramnios. AQP1 may play a critical role in regulating pregnancy outcome and maternal-foetal fluid homeostasis. Changes in AQP1 expression may lead to compensatory alterations in AQP8 and AQP9 expression in the placenta.
\end{abstract}

Keywords Aquaporin $\cdot$ Pregnancy outcome $\cdot$ Amniotic fluid $\cdot$ Placenta $\cdot$ Foetal membrane

\section{Introduction}

The homeostasis of amniotic fluid (AF) exchange between matrix and foetus plays a vital role in a successful pregnancy, as either polyhydramnios (excess AF) or oligohydramnios (insufficient AF) may increase foetal morbidity and mortality during the perinatal stage (Ducza et al. 2017). However, the underlying cellular and molecular mechanisms of solute and water transport between the foetal and maternal compartments remain elusive and require investigation.

During the latter period of gestation, AF is mainly derived from foetal urine and a portion of the lung fluid (Brace and Cheung 2014). The major mechanisms by which fluid is removed from the amniotic cavity are foetal swallowing and intramembranous absorption (Harman 2008), which involves in the transfer of amniotic water and solutes between the

Xueqiong Zhu

zjwzzxq@163.com

1 Department of Obstetrics and Gynecology, The Second Affiliated Hospital of Wenzhou Medical University, No. 109 Xueyuan Xi Road Wenzhou, Zhejiang 325027, China amnion and chorion and the entrance of amniotic water and solutes into underlying foetal blood vessels (Brace and Cheung 2014). This process primarily regulates AF volume (Anderson et al. 2013). Aquaporins (AQPs), small integral membrane proteins with a monomeric size ranging from 26 to $34 \mathrm{kDa}$ (Gonen and Walz 2006, Carbrey and Agre 2009), act as water channels and were reported to be specifically crucial in governing the $\mathrm{AF}$ volume (Hua et al. 2013). To date, a total of $13 \mathrm{AQP}$ proteins (AQP0 to AQP12) have been identified in mammals (Verkman 2011). Each monomeric AQP contains a pore that osmotically facilitates the movement of water across the cell membrane.

AQP1, expressed mainly in the amnion epithelium, chorion cytotrophoblasts and placental vessels (Zhu et al. 2010), is important for the osmotic movement of water across the barrier between the endothelium and epithelium (Mobasheri and Marples 2004). Mann et al. showed that transgenic AQP1knockout $\left(\mathrm{AQP}^{-/}{ }^{-}\right.$) mice developed an increased $\mathrm{AF}$ volume and reduced AF osmolality (Mann et al. 2005), suggesting that the loss of AQP1 causes idiopathic polyhydramnios. However, the authors did not observe the changes in AF volume and osmolality in mice with $A Q P 1$ depletion during different gestational days. Intriguingly, this group subsequently 
discovered that in pregnancies with polyhydramnios, AQP1 expression was enhanced in all regions of the foetal membrane, demonstrating that alterations in AQP1 expression might be a compensatory response but not the primary aetiolgy of idiopathic polyhydramnios (Mann et al. 2006). Additionally, AQP3, AQP8 and AQP9 expressions have been detected in both the placenta and foetal membranes, indicating that these molecules could play a vital role in maternal-foetal fluid exchange (Prat et al. 2012; Zhang et al. 2012b). Our previous studies indicated that the expression of AQP1, AQP3, AQP8 and AQP9 in foetal membranes was dramatically reduced in pregnant women diagnosed with isolated oligohydramnios (Zhu et al. 2009, Jiang et al. 2012). However, an association between expression of AQP1 and other AQPs in patients with a normal AF volume and patients with isolated oligohydramnios has not been established.

Recently, the $A Q P^{--}$mouse model was characterized as a powerful approach for investigating the physiological role and function of AQPs. Using $A Q P 8^{-/-}$mice, Su et al. showed that the mRNA expression of AQP1, AQP11 and AQP12 but not AQP5, was significantly decreased in neonatal mouse ovaries (Su et al. 2013). Similarly, another study dissected starved $A Q P T^{-}$mice and found that $\mathrm{AQP} 1$ expression was upregulated in the capillaries of white adipose tissue in response to prolonged starvation (Skowronski et al. 2016). However, the effects of $A Q P 1$ gene knockout on pregnancy rate and outcome in female mice as well as the expression of other AQP proteins (AQP3, AQP8 and AQP9) in both the placenta and foetal membranes of pregnant $A Q P 1^{-/-}$mice have not been investigated until now.

Therefore, a transgenic $A Q P 1^{-/-}$mouse model was generated to observe the effects of AQP1 depletion on the following gestation-related parameters on different gestational days: maternal pregnancy rate, foetal development and $\mathrm{AF}$ volume and osmolality. In addition, both the placenta and foetal membranes were collected to measure the mRNA and protein expression profiles of AQP3, AQP8 and AQP9 in mice after $A Q P 1$ depletion. Moreover, the correlation among the protein expression of AQP1 and other AQPs in the placenta and foetal membranes of patients with isolated oligohydramnios were also explored using an immunohistochemical method. Finally, after using small interfering RNA (siRNA) to interfere with AQP1 expression in human amnion epithelial WISH cells, the mRNA and protein expression levels of AQP3, AQP8 and AQP9 were examined.

\section{Materials and methods}

\section{Transgenic $A Q P 1^{-/-}$mice}

$A Q P 1^{-/-}$mice were established through intercrossing $A Q P 1$ heterozygous mice overnight (Ma et al. 1998). AQPI heterozygous $\left(A Q P 1^{+-}\right)$mice were donated by Prof. Yuanlin Song from Zhongshan Affiliated Hospital of Fudan University. $A Q P 1^{-/-}$and wild-type $A Q P 1\left(A Q P 1^{+/+}\right)$mice were mated separately. Gestational day $0.5(0.5 \mathrm{GD})$ was defined as the day when a copulation plug was observed, with normal pregnant mice delivering foetuses at term on $19 \mathrm{GD}$ to 20 GD. Meanwhile, the copulation plug and pregnancy rates were defined as the number of female mice with a copulation plug/number of total mice and the number of pregnancy/ number of total mice, respectively. These two rates were recorded. Concept uses were collected from pregnant $A Q P 1^{-/-}$ and $A Q P 1^{+/+}$mice at $9.5 \mathrm{GD}$ (early pregnancy), $13.5 \mathrm{GD}$ (middle pregnancy) and 16.5 GD (late pregnancy).

All mice, which were 6-8 weeks old, were kept under a12h light/dark cycle at a temperature of $23 \pm 1{ }^{\circ} \mathrm{C}$. A standard diet and deionized water were freely accessible to the mice. All animal experiments were carried out according to the Guide for the Care and Use of Laboratory Animals published by the United States National Institutes of Health. Protocols were approved by the Animal Care and Use Committee of Wenzhou Medical University.

\section{Detection of AF volume; foetus, amnion and placenta weights; and placental area}

Five pregnant $A Q P 1^{-/-}$pregnant mice and five pregnant $A Q P 1^{+/+}$mice at each gestational day $(9.5 \mathrm{GD}, 13.5 \mathrm{GD}$ and 16.5GD) were used for this study. At the appropriate gestational age, caesarean section was performed on the two groups of mice, and each gestational sac was carefully separated. The number of embryos per pregnant mouse and macroscopic atrophy were recorded at 9.5 GD, 13.5 GD and 16.5 GD. Each gestational sac was weighed and then ruptured. After the AF had been collected into an Eppendorf tube, the foetus, foetal membrane (including both the amnion and chorion) and placenta were weighed. These tissues were collected from foetuses on each gestational day (GD) and stored at $-80{ }^{\circ} \mathrm{C}$ for further study. The placental area was calculated after measuring the diameter by using the formula: $S=\pi \times\left(1 / 2 \times\right.$ diameter $^{2}$. The AF mass was estimated by determining the difference in weight before and after-rupture.

\section{Determination of AF osmolality and composition}

AF collected from each sac was centrifuged at $3000 \mathrm{rpm}$ for 10 min to remove cellular debris. Subsequently, the AF from each litter of the same genotype was mixed and used to determine the AF osmolality and composition. The cryoscopic method was used to measure AF osmolality with automatic freezing point osmometer (FM-8P, China). Glucose and total protein in the $\mathrm{AF}$ were detected by the biuret method, and urea and creatinine levels were examined by enzymic methods. The electrode method was conducted with o-cresolphthalein 
complexone on an automatic biochemical analyser (ADVIA2400, USA) to determine the concentrations of electrolytes $\left(\mathrm{Na}^{+}, \mathrm{K}^{+}, \mathrm{Cl}^{-}\right)$and another ion $\left(\mathrm{Ca}^{2+}\right)$.

\section{Cell culture}

Human amniotic epithelial cells (WISH cells) were purchased from the Type Culture Collection of the Chinese Academy of Medical Sciences (Shanghai, China). The cells were cultured in Dulbecco's modified eagle's medium (DMEM) (Gibco, USA) supplemented with $10 \%$ foetal bovine serum (Gibco, USA) and a100 $\times$ Pen-Strep solution (Invitrogen, USA). The cells were incubated at $37{ }^{\circ} \mathrm{C}$ in a humidified atmosphere containing $5 \%$ $\mathrm{CO}_{2}$. The culture medium was replaced once every 2 days.

\section{AQP1 siRNA transfection}

Both AQP1 siRNA and control siRNA were purchased from GenePharma (Shanghai, China). The sequence of AQP1 siRNA was 5'-GCU GUA CUC AUC UAC GAC UTT, and the antisense sequence was 5'-AGU CGU AGA UGA GUA CAG CTT. The control siRNA sequence was 5'-UGA CC UCA ACU ACA UGG UGT T, and the antisense sequence was 5'-AAC CAU GUA GUU GAG GUC ATT. WISH cells were cultured to a confluence of $50 \%$ and subsequently transfected with either AQP1 siRNA or control siRNA at $40 \mathrm{nM}$ using Lipofectamine 2000 (Invitrogen, USA) in DMEM without foetal bovine serum following the manufacturer's protocol. The media were changed after $6 \mathrm{~h}$ of incubation and transfected cells were cultured for another $48 \mathrm{~h}$ for subsequent studies.

\section{Quantitative reverse transcription polymerase chain reaction analyses}

Total RNA was extracted from the foetal membrane, placenta and WISH cells using TRIzol in accordance with the manufacturer's protocol. The absorbance of the RNA at $260 \mathrm{~nm}$ and $280 \mathrm{~nm}$ was quantified by spectrometry. From $1 \mu \mathrm{g}$ of total RNA, cDNA was synthesized using a reverse transcription kit following the manufacturer's instructions (Thermo Scientific, Wilmington, USA). Each quantitative RT-PCR sample contained $5 \mu \mathrm{L}$ of
SYBRGreen Master Mix (TransStart TipTop), $1 \mu \mathrm{L}$ of cDNA, $0.5 \mu \mathrm{L}$ of primer pairs complementary to AQPs or GAPDH, and diethyl pyrocarbonate (DEPC) $\mathrm{H}_{2} \mathrm{O}$ at a volume of $10 \mu \mathrm{L}$, and reactions were carried out on a Light Cycler480 (Roche, France). The cycling parameters were as follows: $95^{\circ} \mathrm{C}$ for $5 \mathrm{~min}$, followed by 40 cycles of denaturation at $95^{\circ} \mathrm{C}$ for $20 \mathrm{~s}$, annealing at $58^{\circ} \mathrm{C}$ for $1 \mathrm{~min}$ and extension at $72{ }^{\circ} \mathrm{C}$ for $20 \mathrm{~s}$. Table 1 provides sequences of the primer sets for AQP1, AQP3, AQP8, AQP9 and GAPDH in detail. All transcripts were independently quantified three times. Relative gene expression levels were determined by using the comparative cycle threshold $\left(2^{\triangle \Delta} \mathrm{Ct}\right)$ method, and GAPDH was used as a normalization reference.

\section{Western blotting}

Placental and foetal membrane tissues and WISH cells were separately homogenized and lysed in radio immunoprecipitation assay (RIPA) buffer (Beyotime, China) supplemented with protease inhibitor cocktail (Thermo, USA). The lysate concentrations were determined by bicinchoninic acid (BCA) protein assay. Then, samples containing $40 \mu \mathrm{g}$ of protein were separated by $12 \%$ sodium dodecyl sulphate-polyacrylamide gel electrophoresis (SDSPAGE), and the proteins were then transferred onto a polyvinylidene fluoride (PVDF) membrane (Millipore, USA). The membranes were blocked for $2 \mathrm{~h}$ with $5 \%$ skimmed milk in Tris-buffered saline with $0.1 \%$ Tween-20 (TBS-T, pH 7.4) at room temperature and then incubated at $4{ }^{\circ} \mathrm{C}$ overnight with a primary antibody. Membranes were incubated with the following primary antibodies at $4 \mathrm{C}$ overnight: monoclonal mouse antiAQP1 antibody (1:1000, sc-25287, Santa Cruz, USA), polyclonal rabbit anti-AQP3 antibody (1:500, ab125219, Abcam, USA), polyclonal rabbit anti-AQP8antibody (1:500, ab203682, Abcam), monoclonal mouse anti-AQP9 antibody (1:1000, sc74409, Santa Cruz, USA), antibody against endogenous $\alpha$ Tubulin was used as an internal control (1:5000, AF0001, Beyotime, China). The membranes were rinsed and probed with horseradish-peroxidase-conjugated secondary antibody (Biosharp, China) diluted 1:5000 for $2 \mathrm{~h}$ at room temperature. Finally, immunoreactive bands containing target proteins were visualized with enhanced chemiluminescence (ECL) substrate (Thermo, USA), and images were captured with an Amersham Imager 600 system (General Electric Company, USA).
Table 1 Primers of AQPs and GAPDH for murine placentas and foetal membranes

\begin{tabular}{lll}
\hline Gene & Forward primer $\left(5^{\prime}-3^{\prime}\right)$ & Reverse primer $\left(3^{\prime}-5^{\prime}\right)$ \\
\hline AQP1 & AGCAGCGACTTCACAGAC & CTATTTGGGCTTCATCTCC \\
AQP3 & ATTGTCTCCCCACTCCTG & TCACATTCTCTTCCTCGG \\
AQP8 & TAAGCCCCATTCTCCATT & AGTAGCCAGCCATCACAG \\
AQP9 & CTTCCACCATCCTTCCAC & TGAGCAATAGAGCCACATC \\
GAPDH & AAGAAGGTGGTGAAGCAGG & GAAGGTGGAAGAGTGGGAGT \\
\hline
\end{tabular}

$A Q P$, aquaporin; $G A P D H$, glyceraldehyde-3-phosphate dehydrogenase 


\section{Case selection and diagnostic criteria for oligohydramnios}

To detect correlations between the expression of AQP1 and other AQPs when AQP1 and other AQPs were decreased, a total of 30 patients with singleton pregnancies who received elective caesarean delivery were enrolled in this study; among these patients, 15 patients were identified as having oligohydramnios, while the other 15 had a normal AF volume. The gestational age of the pregnant women ranged from 37 and 40 weeks. Women were excluded when at least one of the following conditions was met: foetal abnormalities; a foetus small for the gestational age; premature rupture of the membranes; restricted foetal growth; treatment with several medications (including those used for cervical ripening, augmentation or labour induction); and diagnosis with complications that might influence the AF, such as hypertension, diabetes, cardiovascular disorders and autoimmune diseases. Ethical approval was received from the Ethical Committee of the Second Affiliated Hospital of Wenzhou Medical University. All subjects agreed to the study and provided written informed consent before starting the study.

Before delivery, oligohydramnios was defined as an $\mathrm{AF}$ index $(\mathrm{AFI})<5 \mathrm{~cm}$ using ultrasound measurement, as a normal AFI ranges from to 8 to $18 \mathrm{~cm}$ (Phelan et al. 1987; Zhang et al. 2004). During delivery, the AF volume (AFV) was measured. An AFV less than $300 \mathrm{~mL}$ indicated oligohydramnios, while an AFV from 300 to $2000 \mathrm{~mL}$ indicated a normal AFV (Zhu et al. 2009).

\section{Immunohistochemical staining}

The placenta and foetal membranes were isolated from patients in the normal group and patients with oligohydramnios and fixed in a $4 \%$ paraformaldehyde solution. These tissues were embedded in paraffin and sliced into sections at a thickness of $5 \mu \mathrm{m}$. Subsequently, the sections were dried, deparaffined and rehydrated in an ethanol gradient. Then, tissue slides were washed with phosphate-buffered saline (PBS), placed in a $10 \mathrm{mM}$ citrate solution $(\mathrm{pH} 6.0)$ and heated at $100{ }^{\circ} \mathrm{C}$ in a microwave oven for antigen retrieval. Endogenous peroxidase activity was blocked with $3 \% \mathrm{H}_{2} \mathrm{O}_{2}$ at room temperature, and nonspecific binding was prevented via incubation with a 5\% blocking bovine serum albumin solution. Tissue sections were then incubated with primary antibodies overnight at $4{ }^{\circ} \mathrm{C}$. The following antibodies were used for immunohistochemical (IHC) staining: monoclonal anti-AQP1 mouse antibody (1:100, sc-25287, Santa Cruz, USA), polyclonal rabbit anti-AQP3 antibody (1:100, ab125219, Abcam, USA), polyclonal rabbit antiAQP8antibody (1:300, ab203682, Abcam, USA) and monoclonal mouse anti-AQP9 antibody (1:200, GTX47915, GeneTex, USA). The tissues were then incubated with secondary antibody for $20 \mathrm{~min}$ at room temperature, followed by incubation with diaminobenzidine as a chromogen for the appropriate duration. After washing with PBS for three times, the tissue sections were counterstained in haematoxylin, dehydrated, cleared and mounted in dibutyl phthalate polystyrene xylene. At least 10 representative staining fields were chosen under a microscope (Olympus-FM10, Japan), and all immunopositive cells in these fields were analysed at random; the proportion of AQP-positive cells was determined for each case (Craciun and Domsa 2017).

\section{Statistical analyses}

SPSS 19.0 (Chicago, IL) was used for statistical analysis. Differences in the copulation plug and pregnancy rates were analysed by chi-square test. Quantitative data are expressed as the mean \pm standard deviation (SD). The statistical significance of differences in AF volume, osmolality and composition; feotal weight; amnion weight; placental area; and weight between the $A Q P 1^{-/-}$and $A Q P 1^{+/+}$mice were assessed by analysis of variance (ANOVA). Multiple comparisons were carried out by using a post hoc least significant difference (LSD) test. Correlation analysis of the expression of AQP1 and other AQPs was conducted using Pearson correlation analysis for normally distributed data; otherwise, the Spearman correlation test was used. A two-sided $P<0.05$ indicated a statistically significant difference.

\section{Results}

\section{AQP1 deficiency reduces fertility in mice}

First, we explored fertility in mice after $A Q P 1$ depletion. We found that pregnant $A Q P 1^{-/-}$mice exhibited a reduced copulation plug rate $(50 \%, 30 / 60)$ compared with that in pregnant $A Q P 1^{+/+}$mice $(90 \%, 54 / 60)$, suggesting that AQP1 depletion led to a decrease in the copulation plug rate $\left(\chi^{2}=4.09, P=\right.$ 0.043). The pregnancy success rate was higher in $A Q P 1^{+/+}$ mice $(94.4 \%, 51 / 54)$ than in wild-type controls $(33.3 \%, 10 /$ $\left.30, \chi^{2}=6.60, P=0.01\right)$. However, the numbers of macroscopic atrophic embryos per pregnancy recorded in $A Q P I^{-/-}$mice and $A Q P I^{+/+}$mice at each gestational age were no different. These results show that AQP1 deficiency reduces reproductive performance in female mice.

\section{AQP1 knockout increases AF weight and decreases AF osmolality in mice}

We further determined whether AQP1 depletion affects the volume, osmolality and composition of the $\mathrm{AF}$ in mice at different stages of pregnancy. The AF volume was not determined, and the placenta and foetal membrane were not 
dissected as they had not yet formed in the gestational sac at 9.5 GD. There was no significant difference in the AFV between $A Q P 1^{-/-}$and $A Q P 1^{+/+}$mice at $13.5 \mathrm{GD}(P>0.05$, Table 2). Intriguingly, the AF weight was dramatically higher in $A Q P 1^{-}$ mice than in $A Q P 1^{+/+}$mice at $16.5 \mathrm{GD}(P<0.05$, Table 3$)$.

No significant difference in AF osmolality or total protein, glucose, urea, creatinine or ion $\left(\mathrm{Na}^{+}, \mathrm{K}^{+}, \mathrm{Cl}^{-}\right.$and $\left.\mathrm{Ca}^{2+}\right)$ concentrations was observed between the two groups at $13.5 \mathrm{GD}$ (Table 2). Consistently, there was also no significant difference in the AF composition between the two groups at $16.5 \mathrm{GD}$ (Table 3 ), but the $A Q P 1^{-1-}$ embryos had a lower AF osmolality than their $A Q P 1^{+/+}$counterparts at 16.5 GD $(P<0.05$, Table 3$)$.

\section{The placental weight at $13.5 \mathrm{GD}$ and foetal weight at $16.5 \mathrm{GD}$ were increased in $A Q P 1^{-1-}$ mice}

Next, we measured the wet weights of the foetus, placenta and foetal membrane as well as the area of the placenta in mice after AQP1 depletion at different stages of pregnancy. The foetal and foetal membrane weights and calculated placental areas did not differ among foetuses from $37 \mathrm{AQP1^{-/- }}$ mice at 13.5 GD $(P>0.05$, Table 2$)$. However, the placental weight of the foetuses of $37 \mathrm{AQP1^{-/- }}$ mice was higher than that of the foetuses of $40 A Q P 1^{+/+}$littermates at $13.5 \mathrm{GD}(P<0.05$, Table 2). At $16.5 \mathrm{GD}$, there were no significant differences in the foetal membrane, placenta weights or placental area between $41 \mathrm{AQP1}^{-/-}$and $42 \mathrm{AQP1}^{+/+}$littermates $(P>0.05$, Table 3$)$. Interestingly, the weight of foetuses from 41 $A Q P 1^{-1-}$ mice was increased compared with that of foetuses from 42 age-matched $A Q P 1^{+/+}$counterparts at $16.5 \mathrm{GD}$ $(P<0.05$, Table 3$)$.

\section{Differential expression of AQP8 and AQP9 in the placenta and foetal membrane of $A Q P 1^{-1-}$ mice}

The expression of AQPs in the placentas of pregnant $A Q P 1^{-/-}$ and $A Q P 1^{+/+}$mice at $13.5 \mathrm{GD}$ and $16.5 \mathrm{GD}$ was analysed at both the transcriptional and translational levels. As determined by quantitative reverse transcription polymerase chain reaction (qRT-PCR), AQP1 mRNA expression was not detected in the placentas of $A Q P 1^{-/-}$mice but was observed in $A Q P 1^{+/+}$mice at both $13.5 \mathrm{GD}$ and $16.5 \mathrm{GD}$ (Fig. $1 \mathrm{a}-\mathrm{b}$, Table 4). The placental mRNA levels of AQP3 and AQP8 were not significantly different between the two groups at both 13.5 GD and 16.5 GD (Fig. 1a-b, Table 4). Compared to the $A Q P 1^{+/+}$mice, there was no apparent difference in the placental mRNA expression of AQP9 at $13.5 \mathrm{GD}$ in $A Q P 1^{-/-}$ mice, but the AQP9 mRNA level in the placenta was lower in the $A Q P 1^{-/-}$mice at 16.5 GD (Fig. 1a-b, Table 4).

The qRT-PCR results further demonstrated that AQP1 was not expressed in the foetal membranes of $A Q P 1^{-/-}$mice, unlike $A Q P 1^{+/+}$mice (Fig. 1c-d, Table 5). No significant difference in the mRNA expression of AQP3 in the foetal membrane was found between these two groups at 13.5 GD and 16.5 GD (Fig. 1c-d, Table 5). However, the mRNA level of AQP8 in the foetal membranes of the $A Q P 1^{-/}$mice was significantly elevated compared with that of the $A Q P 1^{+/+}$mice (Fig. 1c-d, Table 5). Conversely, AQP9 mRNA expression was reduced in the foetal membranes of $A Q P 1^{-/-}$mice at both 13.5 GD and 16.5 GD (Fig. 1c-d, Table 5). Western blotting data validated that these changes in the mRNA expression of AQP1, AQP3, AQP8 and AQP9 in $A Q P 1^{-/-}$mice were consistent with changes in their proteins expression in the placenta and foetal membranes at 13.5 GD and 16.5 GD (Fig. 2a-d').
Table 2 Changes in AF, osmolality, composition concentration and foetus, foetal membrane and placenta weights as well as placenta areas among the AQP1 homozygote and wildtype groups at $13.5 \mathrm{GD}$ (mean \pm SD)

\begin{tabular}{|c|c|c|}
\hline Parameters & $\mathrm{AQP}^{+/+}$ & $\mathrm{AQP}^{-1-}$ \\
\hline $\mathrm{AF}(\mathrm{g})$ & $135 \pm 19.2(n=5)$ & $130 \pm 29.1(n=5)$ \\
\hline Osmolality (mOsm/L) & $301 \pm 24.7(n=5)$ & $302 \pm 29.0(n=5)$ \\
\hline Total protein $(\mathrm{g} / \mathrm{L})$ & $3.40 \pm 0.990(n=5)$ & $3.62 \pm 0.420(n=5)$ \\
\hline Glucose (g/L) & $2.37 \pm 0.862(n=5)$ & $3.35 \pm 0.861(n=5)$ \\
\hline Urea (mmol/L) & $8.04 \pm 1.61(n=5)$ & $7.31 \pm 1.92(n=5)$ \\
\hline Creatinine $(\mathrm{mmol} / \mathrm{L})$ & $9.83 \pm 1.45(n=5)$ & $10.23 \pm 3.26(n=5)$ \\
\hline $\mathrm{Na}^{+}(\mathrm{mmol} / \mathrm{L})$ & $141 \pm 8.34(n=5)$ & $140.5 \pm 10.7(n=5)$ \\
\hline $\mathrm{K}^{+}(\mathrm{mmol} / \mathrm{L})$ & $6.61 \pm 0.792(n=5)$ & $7.58 \pm 1.27(n=5)$ \\
\hline $\mathrm{Cl}^{-}(\mathrm{mmol} / \mathrm{L})$ & $102 \pm 8.25(n=5)$ & $105 \pm 9.51(n=5)$ \\
\hline $\mathrm{Ca}^{2+}(\mathrm{mmol} / \mathrm{L})$ & $1.81 \pm 0.641(n=5)$ & $1.93 \pm 0.572(n=5)$ \\
\hline Foetus weight (mg) & $140 \pm 19.5(n=41)$ & $132 \pm 36.8(n=37)$ \\
\hline Foetal membrane weight (mg) & $15.9 \pm 3.27(n=41)$ & $16.1 \pm 4.33(n=37)$ \\
\hline Placenta weight (mg) & $65.4 \pm 10.3(n=41)$ & $74.3 \pm 18.0 *(n=37)$ \\
\hline Placental area $\left(\mathrm{mm}^{2}\right)$ & $0.453 \pm 0.0201(n=41)$ & $0.422 \pm 0.0312(n=37)$ \\
\hline
\end{tabular}

Data were analysed by ANOVA. $* P<0.05$ versus wild type $\left(A Q P 1^{+/+}\right.$group)

$G D$, gestational day; $S D$, standard deviation; $A N O V A$, analysis of variance 
Table 3 Changes in AF, osmolality, composition concentration and foetus, foetal membrane and placenta weights as well as placenta areas among the AQP1 homozygote and wildtype groups at $16.5 \mathrm{GD}$ (mean \pm $\mathrm{SD})$

\begin{tabular}{lrl}
\hline Parameters & \multicolumn{1}{l}{$\mathrm{AQP}^{+/+}$} & \multicolumn{1}{l}{$\mathrm{AQP1}^{-/-}$} \\
\hline $\mathrm{AF}(\mathrm{g})$ & $183 \pm 25.5(n=5)$ & $196 \pm 23.3 *(n=5)$ \\
Osmolality $(\mathrm{mOsm} / \mathrm{L})$ & $400 \pm 16.5(n=5)$ & $312 \pm 6.01^{*}(n=5)$ \\
Total protein $(\mathrm{g} / \mathrm{L})$ & $2.86 \pm 0.412(n=5)$ & $2.69 \pm 0.642(n=5)$ \\
Glucose $(\mathrm{g} / \mathrm{L})$ & $1.83 \pm 0.621(n=5)$ & $1.86 \pm 0.761(n=5)$ \\
Urea $(\mathrm{mmol} / \mathrm{L})$ & $7.43 \pm 1.10(n=5)$ & $7.07 \pm 1.17(n=5)$ \\
$\mathrm{Creatinine}(\mathrm{mmol} / \mathrm{L})$ & $13.0 \pm 3.36(n=5)$ & $12.7 \pm 5.57(n=5)$ \\
$\mathrm{Na}^{+}(\mathrm{mmol} / \mathrm{L})$ & $146 \pm 4.28(n=5)$ & $142.4 \pm 4.95(n=5)$ \\
$\mathrm{K}^{+}(\mathrm{mmol} / \mathrm{L})$ & $7.82 \pm 1.84(n=5)$ & $8.18 \pm 1.81(n=5)$ \\
$\mathrm{Cl}^{-}(\mathrm{mmol} / \mathrm{L})$ & $109 \pm 6.03(n=5)$ & $108.6 \pm 4.70(n=5)$ \\
$\mathrm{Ca}^{2+}(\mathrm{mmol} / \mathrm{L})$ & $1.73 \pm 0.472(n=5)$ & $1.40 \pm 0.361(n=5)$ \\
Foetus weight $(\mathrm{mg})$ & $556 \pm 121(n=42)$ & $656 \pm 115 *(n=40)$ \\
Foetal membrane weight $(\mathrm{mg})$ & $30.1 \pm 7.22(n=42)$ & $31.2 \pm 6.58(n=40)$ \\
Placenta weight $(\mathrm{mg})$ & $79.2 \pm 11.6(n=42)$ & $79.9 \pm 9.91(n=40)$ \\
$\mathrm{Placental} \mathrm{area}\left(\mathrm{mm}^{2}\right)$ & $0.412 \pm 0.0323(n=42)$ & $0.451 \pm 0.0412(n=40)$ \\
\hline
\end{tabular}

Data were analysed by ANOVA. $* P<0.05$ versus wild type $\left(A Q P 1^{+/+}\right.$group $)$

$G D$, gestational day; $S D$, standard deviation; $A N O V A$, analysis of variance

\section{AQP9 expression is decreased in AQP1 siRNA-transfected WISH cells}

To further confirm our findings in $A Q P 1^{-/-}$mice, WISH cells were transfected with $40 \mathrm{nM}$ AQP1 siRNA. Compared with the control siRNA-transfected cells, AQP1 siRNA-transfected

a

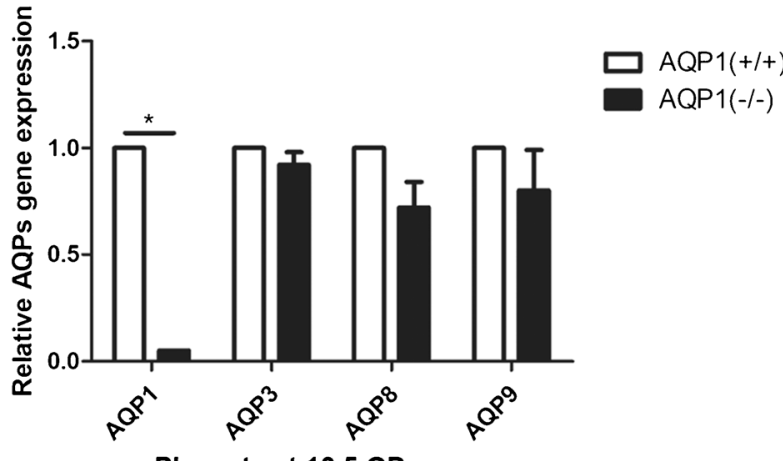

C

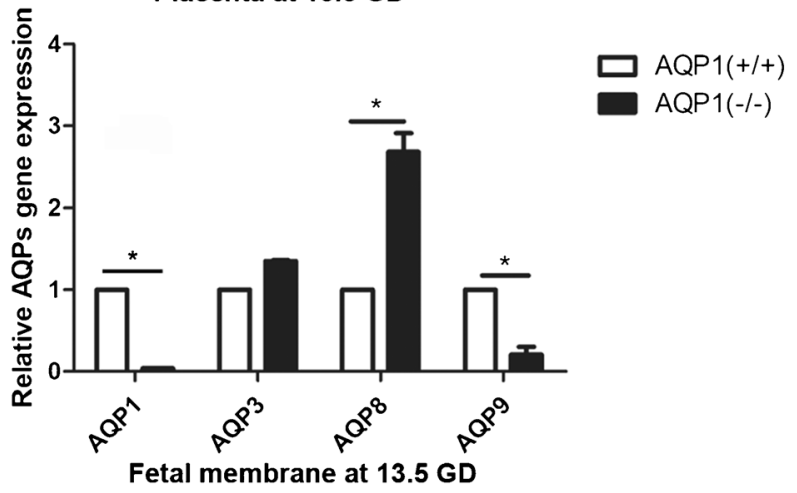

Fig. 1 AQP1 depletion in mice causes a decrease of AQP9 mRNA in placenta and foetal membrane and an increase of AQP8 mRNA in foetal membrane. Relative mRNA expression of AQP1, AQP3, AQP8 and AQP9 was measured by qRT-PCR in placenta at $13.5 \mathrm{GD}$ (a) and cells exhibited AQP1 mRNA and protein levels reduced by $79 \%$ and $81 \%$, respectively (Fig. 3a-b', Table 6), and the mRNA and protein expression of AQP9 was significantly reduced (Fig. 3a-b', Table 6). Although the AQP3 mRNA expression was lower in AQP1 siRNA-transfected WISH cells (Fig. 3a, Table 6), AQP3 protein expression was not

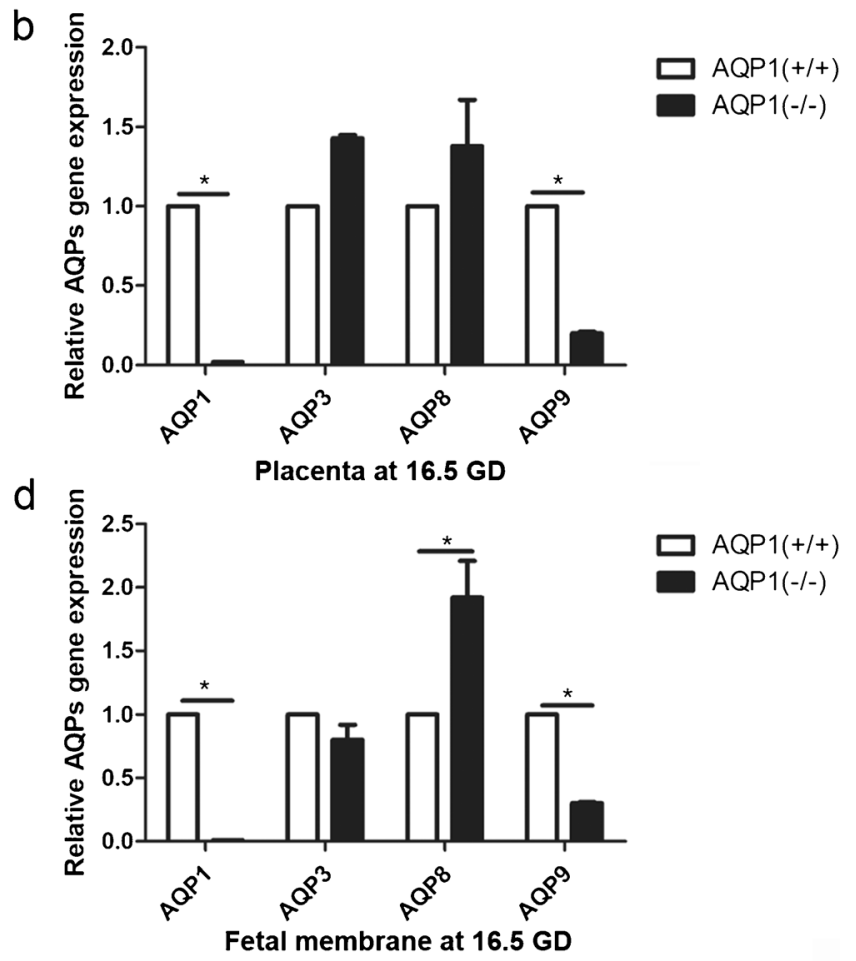

16.5GD (b). Relative mRNA expression of AQP1, AQP3, AQP8 and AQP9 was detected using qRT-PCR in foetal membrane at $13.5 \mathrm{GD}$ (c) and $16.5 \mathrm{GD}(\mathrm{d}) * P<0.05$ vs wild type mice 
Table 4 Relative mRNA expression of AQP1, AQP3, AQP8 and AQP9 in placenta at 13.5 GD and 16.5 GD (mean \pm SD)

\begin{tabular}{|c|c|c|c|c|c|}
\hline Parameters & Cases & AQP1 & AQP3 & AQP8 & AQP9 \\
\hline \multicolumn{6}{|l|}{$13.5 \mathrm{GD}$} \\
\hline $\mathrm{AQP}^{+/+}$ & 41 & 1 & 1 & 1 & 1 \\
\hline $\mathrm{AQP1}{ }^{-/-}$ & 37 & $0.0512 \pm 0.00124^{*}$ & $0.92 \pm 0.0612$ & $0.72 \pm 0.122$ & $0.80 \pm 0.193$ \\
\hline \multicolumn{6}{|l|}{$16.5 \mathrm{GD}$} \\
\hline $\mathrm{AQP} 1^{+/+}$ & 42 & 1 & 1 & 1 & 1 \\
\hline $\mathrm{AQP} 1^{-/-}$ & 40 & $0.0214 \pm 0.00262^{*}$ & $1.43 \pm 0.0215$ & $1.38 \pm 0.291$ & $0.201 \pm 0.0147^{*}$ \\
\hline
\end{tabular}

Data were analysed by ANOVA. $* P<0.05$ versus wild type $\left(A Q P 1^{+/+}\right.$group)

$S D$, standard deviation; ANOVA, analysis of variance

changed after AQP1 downregulation (Fig. 3b-b'). Furthermore, AQP1 downregulation did not alter the mRNA and protein levels of AQP8 in WISH cells (Fig. 3a-b', Table 6). These results demonstrate that AQP1 mainly regulates the expression of AQP9 in WISH cells.

\section{Expression of AQP1 is associated with AQP9 protein levels in oligohydramnios patients}

In this study, patients with oligohydramnios were chosen to determine whether the expression levels of AQP1 and other AQPs are correlated when AQP1 and other AQPs are decreased. The placenta and foetal membranes were immunostained with antibodies against AQP1, AQP3, AQP8 or AQP9 (Fig. 4a-p). AQP1 and AQP9 protein expression was detected in amnion epithelial cells, chorion cytotrophoblasts and placental trophoblasts (Fig. 4a, i, g, o). Compared with patients with a normal AFV, patients with oligohydramnios exhibited dramatically decreased AQP1 and AQP9 expression in the foetal membrane and placental trophoblasts (Table 7, $P<$ 0.05, Fig. 4a-b, i-j, g-h, o-p). Additionally, the expression of AQP3 in placental trophoblasts from patients with oligohydramnios was dramatically decreased (Table 7, $P<$ 0.05, Fig. 4c-d). No significant difference in AQP3 expression in the foetal membrane (Fig. 4k-1), or in AQP8 expression in placental trophoblasts and foetal membrane (Fig. 4e-f, m-n) was observed between the two groups (Table $7, P>0.05$ ). Moreover, among patients with a normal AFV, no significant difference in the expression of AQP1, AQP3, AQP8 or AQP9 was found in the placenta trophoblasts, amnion epithelial cells or chorion (Table 8 and Table $9, P>0.05$ ). In patients with oligohydramnios, AQP9 expression was positively associated with AQP1 expression in both placental trophoblasts (Table 8, $P<0.05, r=0.640$ ) and foetal membranes (amnion epithelial cells and chorion cytotrophoblasts) (Table 9, $P<0.05, r=$ $0.634)$.

\section{Discussion}

AQPs are distributed throughout the male and female reproduction systems, where they facilitate gamete transport, fertilization and early embryo development (Skowronski et al. 2009; Zhang et al. 2012a). An increase in embryo numbers was observed in $A Q P 8^{-1-}$ mice (Sha et al. 2011). Consistently, female $A Q P 8^{-1-}$ mice displayed elevated fertility due to an increase in follicular maturation and ovulation via reduced granulosa cell apoptosis (Su et al. 2010). In contrast, pregnant $A Q P 4^{-1}$ mice displayed reduced fertility and a lower pregnancy rate and litter size. This may be caused by the presence of smaller ovaries containing fewer antral follicles and corpora lutea and a decreased uterine response to gonadotropins in

Table 5 Relative mRNA expression of AQP1, AQP3, AQP8 and AQP9 in foetal membrane at 13.5 GD and 16.5 GD (mean \pm SD)

\begin{tabular}{|c|c|c|c|c|c|}
\hline Parameters & Cases & AQP1 & AQP3 & AQP8 & AQP9 \\
\hline \multicolumn{6}{|l|}{$13.5 \mathrm{GD}$} \\
\hline $\mathrm{AQP} 1^{+/+}$ & 41 & 1 & 1 & 1 & 1 \\
\hline $\mathrm{AQP} 1^{-/-}$ & 37 & $0.0416 \pm 0.00113^{*}$ & $1.35 \pm 0.0128$ & $2.68 \pm 0.232^{*}$ & $0.212 \pm 0.0932^{*}$ \\
\hline \multicolumn{6}{|l|}{$16.5 \mathrm{GD}$} \\
\hline $\mathrm{AQP} 1^{+/+}$ & 42 & 1 & 1 & 1 & 1 \\
\hline $\mathrm{AQP} 1^{-/-}$ & 40 & $0.0123 \pm 0.00137^{*}$ & $0.0814 \pm 0.125$ & $1.92 \pm 0.293^{*}$ & $0.302 \pm 0.0142^{*}$ \\
\hline
\end{tabular}

Data were analysed by ANOVA. $* P<0.05$ versus wild type $\left(A Q P 1^{+/+}\right.$group $)$

$S D$, standard deviation; ANOVA, analysis of variance 
a

$\mathrm{AQP1}$

AQP3

AQP8

AQP9

Tubulin
$28 \mathrm{kDa}$

$31 \mathrm{kDa}$ $27 \mathrm{kDa}$ $29 \mathrm{kDa}$ $55 \mathrm{kDa}$ b

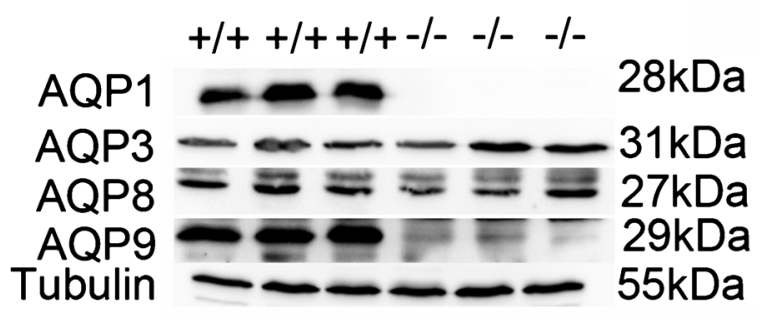

C

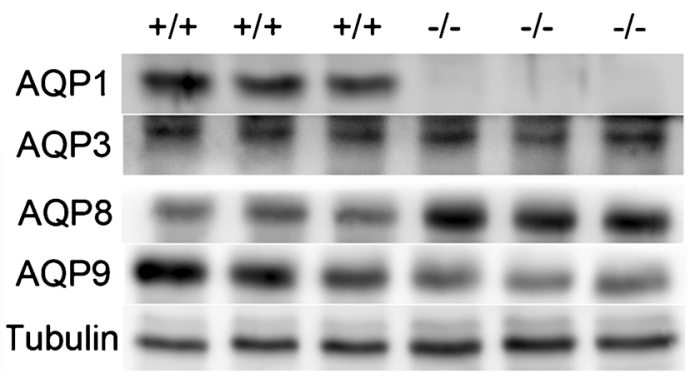

$28 \mathrm{kDa}$

$31 \mathrm{kDa}$

$27 \mathrm{kDa}$

$33 \mathrm{kDa}$

$55 \mathrm{kDa}$ $a^{\prime}$

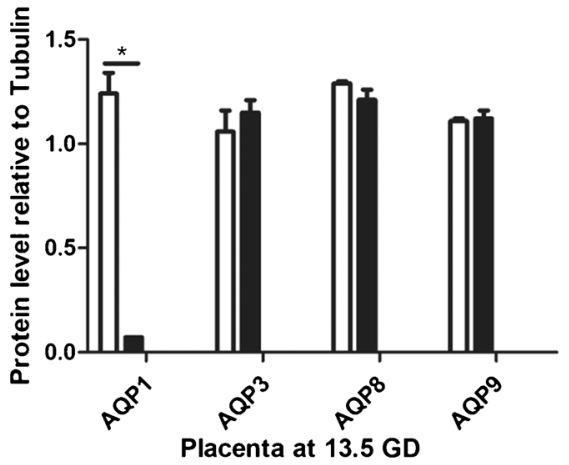

b'

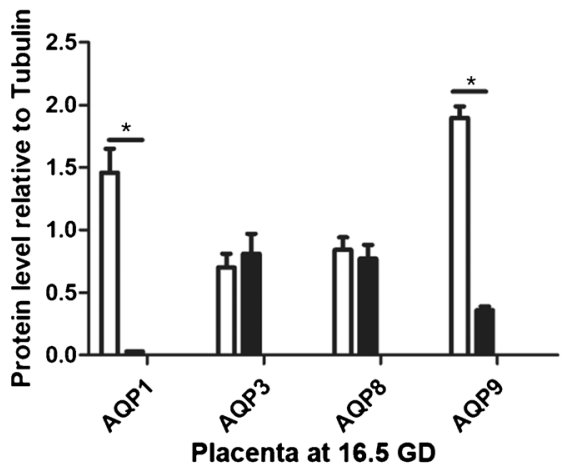

c'

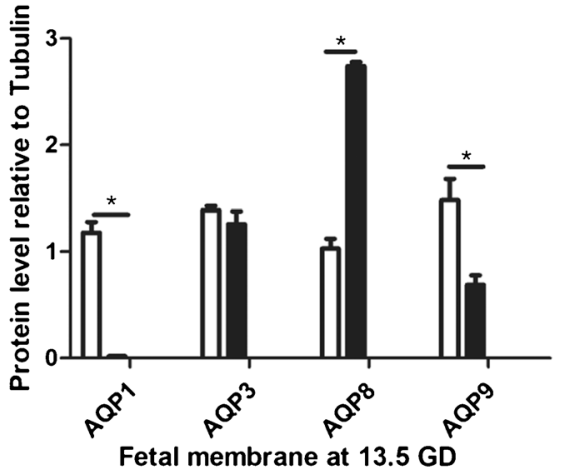

d'

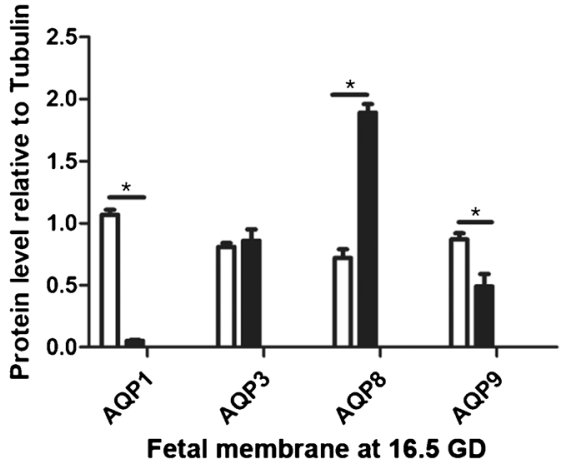

') and 16.5GD (b-- b'). Expression of AQP1, AQP3, AQP8 and AQP9 proteins was determined by western blotting in foetal membrane at 13.5 GD $\left(\mathrm{c}-\mathrm{c}^{\prime}\right)$ and $16.5 \mathrm{GD}\left(\mathrm{d}-\mathrm{d}^{\prime}\right)$. Quantitative data for each AQP protein were presented in the histogram $\left(a^{\prime}-d^{\prime}\right)$

development and maturation of the male reproductive system. AQP1 has been observed in the reproductive tracts of male mammals (Huang et al. 2006). The dysregulation or
In the male reproductive system, water and solute movement play a vital role in balancing the intracavitary environment for
AQP1 knockout mice exhibit a decrease of AQP9 protein placenta and foetal membrane and an increase of AQP8 protein in foetal membrane. Expression of AQP1, AQP3, AQP8 and AQP9 proteins was measured by western blotting in placenta at 13.5 GD (a-a 
a

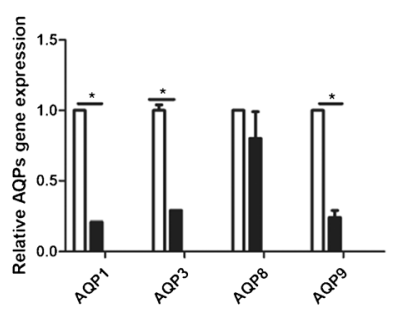

Fig. 3 AQP9 expression is decreased in AQP1 siRNA transfected WISH cells. Relative mRNA expression of AQP1, AQP3, AQP8 and AQP9 was measured by RT-PCR in WISH cells after AQP1 siRNA transfection. $P<0.05$ vs control siRNA transfection (a). Expression of AQP1,

knockdown of AQP1 might lead to male reproductive system disorders. Consistently, AQPs are also distributed in female reproductive tissues. AQP1 is primarily distributed in the vagina, uterus, oviduct, granulosa cells and oocytes. The main function of AQP1 is tubal fluid transport, and AQP1 plays an important role in maintaining the water homeostasis of the oviduct and uterus and facilitates the transport and fertilization of gametes (Gannon et al. 2000). Impairment of AQP1 can lead to decreased fertility in both males and females. In the present study, we revealed a decreased copulation plug rate and successful pregnancy rate in $A Q P 1^{-1-}$ mice, demonstrating that $\mathrm{AQP} 1$ is involved in regulating the function of the female reproductive system. Nevertheless, the number of macroscopic atrophic embryos in $A Q P 1^{-/-}$mice and $A Q P 1^{+/+}$mice did not differ at either 13.5 GD or $16.5 \mathrm{GD}$, suggesting that the AQP1 protein does not affect embryogenesis and development. Thus, further studies should be carried out to specifically elucidate the underlying molecular mechanism of reduced female reproductive performance due to the absence of AQP1 and cellular events responsible for the effect.

In our previous study, AQP1 was detected in placental vascular endothelial cells (Zhu et al. 2009), which may reflect a role in angiogenesis. Herein, we found that the placenta weight of $A Q P 1^{-/}$mice was dramatically higher than that of $A Q P 1^{+/+}$counterparts at $13.5 \mathrm{GD}$, and the embryonic weight of in $A Q P 1^{-/-}$mice was higher than that of $A Q P 1^{+/+}$ mice at $16.5 \mathrm{GD}$. In support of the role of AQP1 in angiogenesis, the placentas of $A Q P 1^{-/-}$mice displayed an altered blood vessel structure, an increased number of trophoblast cells and nodules and enhanced nucleated red blood cell counts (Zheng et al. 2014). Therefore, we speculate that the placentas of b'

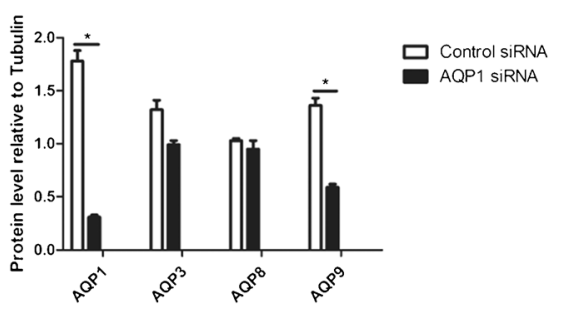

AQP3, AQP8 and AQP9 proteins was detected by western blotting in AQP1 siRNA transfected WISH cell (b). Quantitative data for control siRNA and AQP1 siRNA protein were presented in the histogram $\left(b^{\prime}\right)$

$A Q P 1^{-1-}$ mice exhibit abnormal angiogenesis that results in hyperplasia and oedema. Indeed, an increased AFV and larger placentas were observed in $A Q P 1^{-/-}$mice at $16.5 \mathrm{GD}$, which might create a perfect environment for foetuses in utero and more nutrients to increase foetal weight. Our findings indicate that AQP1 has a vital function in placental and foetal growth.

The foetuses of homozygous $A Q P 1^{-/-}$mice exhibit polyhydramnios (Zheng et al. 2014). The degenerating placentas of $A Q P I^{-1}$ displayed compressive deformation of the blood vessel structure and an increased number of syncytiotrophoblast nodules. Additionally, the permeability of trophoblast cells in AQP1 ${ }^{-/-}$mice was shown to be significantly decreased (Sha et al. 2015). Consistent with these results, our data suggested that female $A Q P 1^{-/-}$mice serve as a model of polyhydramnios. Furthermore, polyhydramnios was observed at $16.5 \mathrm{GD}$ rather than $13.5 \mathrm{GD}$, which is consistent with the occurrence of polyhydramnios in late gestation in humans (Brace 1997). In the latter half of gestation, AF is largely produced from foetal urine and foetal lung secretions. The AF is primarily reabsorbed through foetal swallowing, but the intramembranous pathway also accounts for some AF removal. Several possible mechanisms for the increase in AF volume have been reported (King et al. 1996). Although AQP1 has been detected in pulmonary microvascular endothelial cells and pneumocytes, AQP1 deletion did not influence the production or clearance of alveolar fluid (Verkman et al. 2000, Chou et al. 1999). Furthermore, AQP1-deficient mice showed impaired absorption of renal fluid and the inability to concentrate urine (Chou et al. 1999, Verkman 1999), which may increase urinary flow to the amniotic cavity, suggesting the important role of the AQP1

Table 6 Relative mRNA expression of AQP1, AQP3, AQP8 and AQP9 in control siRNA WISH cell and AQP1 siRNA WISH cell (mean \pm SD)

\begin{tabular}{lllll}
\hline Parameters & AQP1 & AQP3 & AQP8 & AQP9 \\
\hline Control & 1 & 1 & 1 & 1 \\
AQP1 siRNA & $0.211 \pm 0.001^{*}$ & $0.293 \pm 0.002^{*}$ & $0.802 \pm 0.191$ & $0.244 \pm 0.051^{*}$ \\
\hline
\end{tabular}

Data were analysed by ANOVA. $* P<0.05$ versus control group

$S D$, standard deviation; ANOVA, analysis of variance 


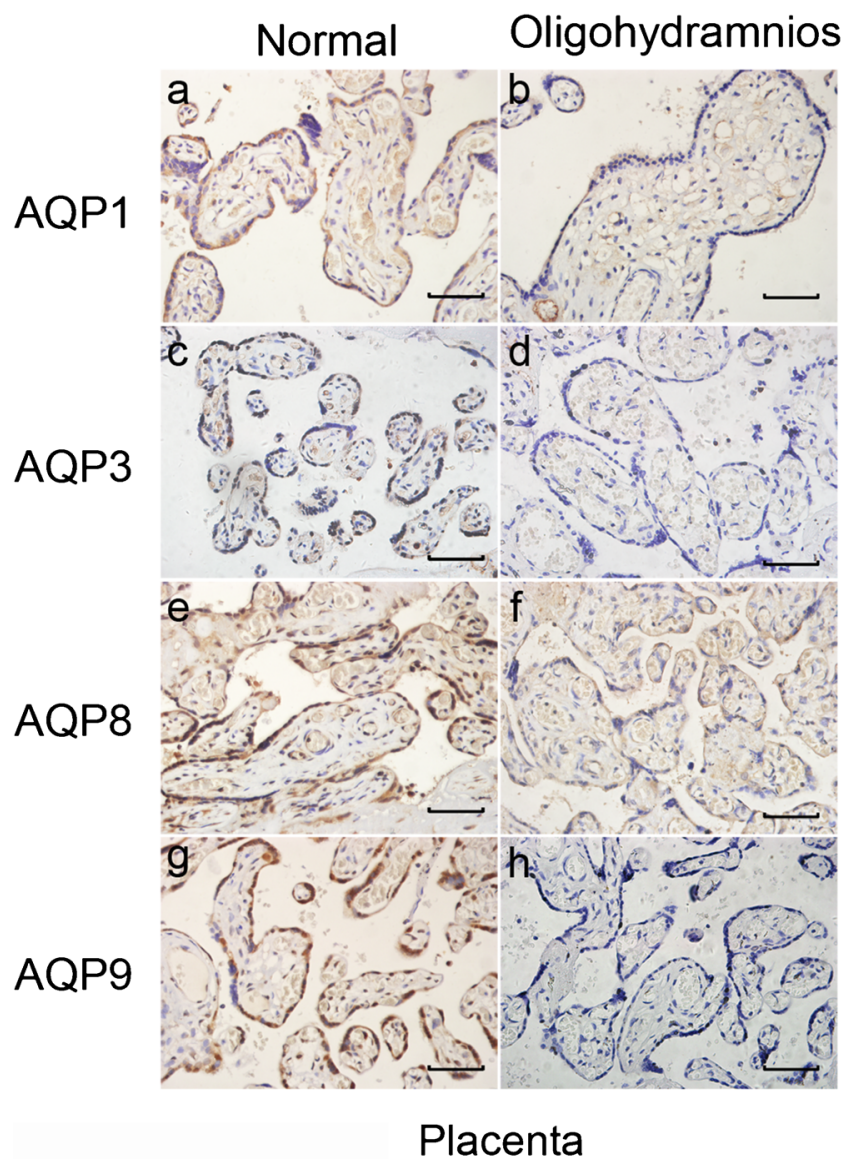

Fig. 4 Expression of AQP1 is associated with AQP9 protein level in oligohydramnios patients. Immunohistochemical staining of AQP1, AQP3, AQP8 and AQP9 was performed in placenta in normal AF volume group and oligohydramnios group $(\mathrm{a}-\mathrm{h})$. Immunohistochemical

protein in the kidney. On the other hand, when AF absorption is decreased, AQP1 may participate in regulating the movement of water in the foetal membranes and placental trophoblast (Zheng et al. 2014), while AQP1 deficiency reduces the fluid resorption capacity. The composition of the $\mathrm{AF}$ was not changed in $A Q P 1^{-/-}$mice at $16.5 \mathrm{GD}$; thus, we speculated that the observed polyhydramnios and decreased AF osmolality were associated with AQP1 (Mann et al. 2002). Changes in

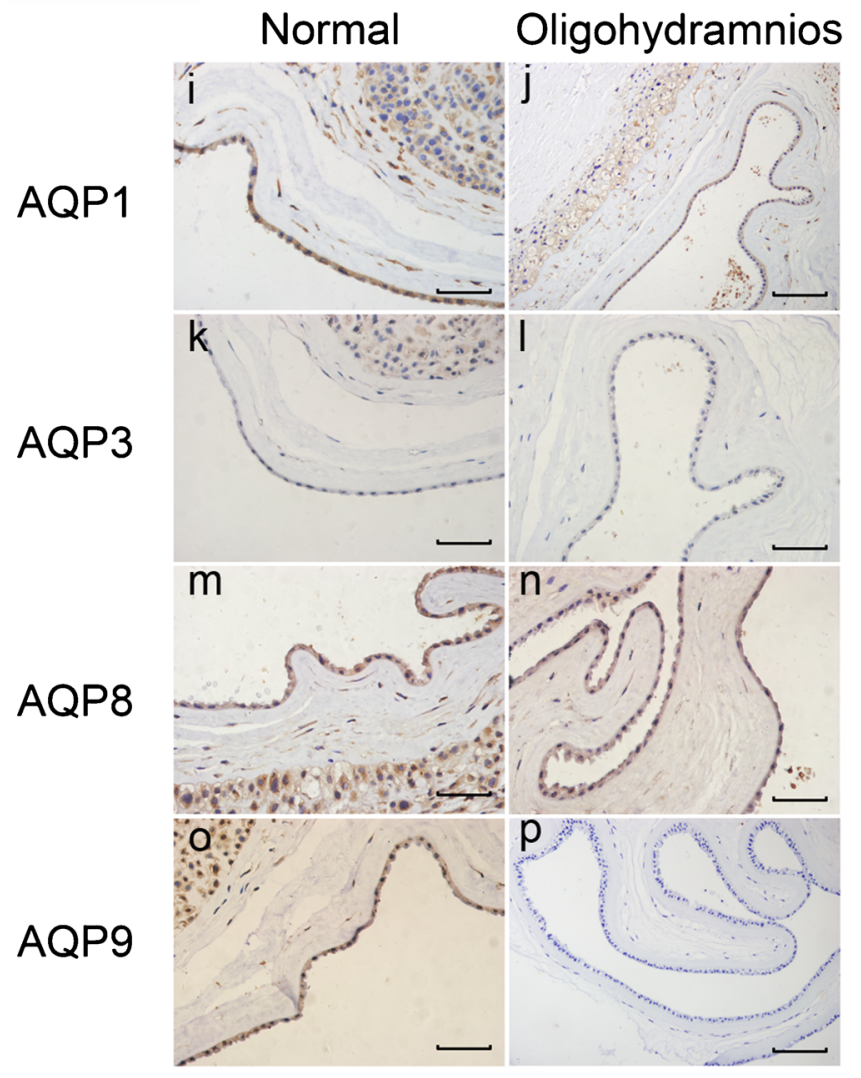

Fetal membrane

staining of $\mathrm{AQP} 1, \mathrm{AQP} 3, \mathrm{AQP} 8$ and $\mathrm{AQP} 9$ was conducted in amnion epithelial cells and chorion in normal AF volume group and oligohydramnios group (i-p). Bar $50 \mu \mathrm{m}$

the AF volume may be due to alterations in AF osmolality caused by AQP1-mediated water transport.

Specifically, AQP1, AQP3, AQP8 and AQP9, which play a vital role in maternal-foetal fluid exchange homeostasis, have been detected in the placenta and foetal membranes (Beall et al. 2007). Compensatory changes in the expression of other AQPs induced by alterations in AQP1 expression were also observed in this study. While AQP8 was upregulated in the foetal

Table 7 Expression of AQP1, AQP3, AQP8 and AQP9 protein in human placenta and foetal membranes in normal amniotic groups and oligohydramnios groups by immunohistochemistry (mean $\pm \mathrm{SD}$ )

\begin{tabular}{|c|c|c|c|c|c|}
\hline Parameters & Cases & AQP1 (\%) & AQP3 (\%) & AQP8 (\%) & AQP9 (\%) \\
\hline \multicolumn{6}{|l|}{ Placenta } \\
\hline Normal & 15 & $87.2 \pm 23.1$ & $72.3 \pm 11.3$ & $90.1 \pm 21.2$ & $88.2 \pm 90.1$ \\
\hline Oligohydramnios & 15 & $56.2 \pm 14.2^{*}$ & $54.2 \pm 19.4^{*}$ & $88.2 \pm 15.4$ & $14.2 \pm 1.34^{*}$ \\
\hline \multicolumn{6}{|l|}{ Foetal membranes } \\
\hline Normal & 15 & $89.2 \pm 20.1$ & $86.2 \pm 13.4$ & $98.2 \pm 13.3$ & $92.1 \pm 6.12$ \\
\hline Oligohydramnios & 15 & $60.2 \pm 18.3^{*}$ & $78.2 \pm 22.4$ & $90.1 \pm 21.4$ & $11.9 \pm 1.14^{*}$ \\
\hline
\end{tabular}

Data were analysed by ANOVA. $* P<0.05$. vs normal amniotic group

$S D$, standard deviation; ANOVA, analysis of variance 
Table 8 The relevance among AQP1 and AQP3, AQP8, AQP9 in placenta trophoblasts of normal group and oligohydramnios group

\begin{tabular}{llllllll}
\hline & \multicolumn{3}{c}{ AQP1 } & & & \multicolumn{3}{c}{ AQP1 } \\
Normal & $n$ & $r$ & $P$ & Oligohydramnios & $n$ & $r$ & $P$ \\
\hline AQP3 & 15 & 0.401 & 0.202 & AQP3 & 15 & 0.171 & 0.582 \\
AQP8 & 15 & 0.342 & 0.393 & AQP8 & 15 & 0.0833 & 0.801 \\
AQP9 & 15 & 0.284 & 0.403 & AQP9 & 15 & 0.640 & $0.018^{*}$ \\
\hline
\end{tabular}

Data were analysed by Pearson correlation analysis, $* P<0.05$

membrane, the expression of AQP9 was reduced in foetal membranes and placenta of $A Q P 1^{-/-}$mice. Hence, upregulation of AQP8 in the foetal membranes after AQP1 depletion may lead to polyhydramnios through a compensatory mechanism, while the expression of AQP9 in the placenta and foetal membranes is decreased after $A Q P 1$ depletion. This phenomenon might be related to the different classifications and biological functions of AQPs. AQP1 and AQP3 play a vital role in passive water movement across the amnion (Damiano 2011) and other studies suggest that AQP8 and AQP9 are fundamental to the regulation of foetal water and solute flow through both intramembranous absorption and placental water transfer from mother to foetus (Wang et al. 2004; Wang et al. 2001). AQP1 and AQP8 are characterized as classical AQPs selectively permeable to only water (Ishibashi et al. 2011), whereas AQP9 functions as an aquaglyceroporin permeable to water, reactive oxygen species, non-polar solutes, metalloids and gases (Madeira et al. 2015; Mukhopadhyay et al. 2014). AQP3 mRNA expression was lower in the AQP1 siRNA-transfected WISH cells, while its protein level was unchanged; this discrepancy between AQP3 protein and mRNA expression is mostly likely the result of biology of gene expression and the regulation of protein synthesis at various levels, such as the posttranscriptional, translational or and posttranslational levels (Tian et al. 2004).

Furthermore, we explored the association between AQP1 and other AQPs in human WISH cells, and found that inhibition of AQP1 expression significantly reduced AQP9 expression. In our previous study (Zhu et al. 2009; Jiang et al. 2012), AQP1 and AQP9 expression in the amnion was decreased in pregnancies with isolated oligohydramnios, so pregnancies with oligohydramnios and a normal AF volume were selected to establish the correlation between AQP1 and AQP9 protein

Table 9 The relevance among AQP1 and AQP3, AQP8, AQP9 in foetal membranes of normal group and oligohydramnios group

\begin{tabular}{lllllllll}
\hline & \multicolumn{3}{c}{ AQP1 } & & & \multicolumn{3}{c}{ AQP1 } \\
Normal & $n$ & $r$ & $P$ & Oligohydramnios & $n$ & $r$ & $P$ \\
\hline AQP3 & 15 & 0.352 & 0.291 & AQP3 & 15 & -0.542 & 0.171 \\
AQP8 & 15 & -0.265 & 0.381 & AQP8 & 15 & 0.245 & 0.482 \\
AQP9 & 15 & 0.548 & 0.0650 & AQP9 & 15 & 0.634 & $0.0214^{*}$ \\
\hline
\end{tabular}

Data were analysed by Pearson correlation analysis, $* P<0.05$ expression. Our results showed that the expression of AQP1 and AQP9 was dramatically decreased in both placental trophoblasts and amnion epithelial cells in oligohydramnios, which suggested that downregulation of AQP1 and AQP9 is an adaptive response to isolated oligohydramnios, which leads to a reduction in intramembranous absorption, maintaining AF homeostasis. On the other hand, AQP1 and AQP3, AQP8 and AQP9 expressions levels in placenta trophoblasts, amnion epithelial cells and the chorion were not significantly correlated in normal pregnant women. However, in oligohydramnios patients, AQP9 expression in the placenta and foetal membranes was positively correlated with AQP1 expression in both placental trophoblasts and amnion epithelial cells.

In summary, while the water channel AQP1 may influence pregnancy outcome and participate in the regulation of AF volume and osmotic pressure, it does not affect embryogenesis and development. In addition, changes in AQP1 may lead to compensatory alterations in the expression of other AQPs in both the placenta and foetal membranes. Further studies should be carried out to clarify this compensatory mechanism in the future.

Funding information This work was supported by grants from Project of National Nature Science Fund of China (grant number 81601319) and Project of Wenzhou Science and Technology (grant number Y20160124).

\section{Compliance with ethical statements}

Conflict of interest The authors declare that they have no conflict of interest.

Ethical approvsal All applicable institutional guidelines for the care and use of animals were followed. All procedures performed in studies involving human participants were in accordance with the ethical standards of the institutional research committee and with the 1964 Helsinki declaration and its later amendments or comparable ethical standards.

Open Access This article is licensed under a Creative Commons Attribution 4.0 International License, which permits use, sharing, adaptation, distribution and reproduction in any medium or format, as long as you give appropriate credit to the original author(s) and the source, provide a link to the Creative Commons licence, and indicate if changes were made. The images or other third party material in this article are included in the article's Creative Commons licence, unless indicated otherwise in a credit line to the material. If material is not included in the article's Creative Commons licence and your intended use is not permitted by statutory regulation or exceeds the permitted use, you will need to obtain permission directly from the copyright holder. To view a copy of this licence, visit http://creativecommons.org/licenses/by/4.0/.

\section{References}

Anderson DF, Jonker SS, Louey S, Cheung CY, Brace RA (2013) Regulation of intramembranous absorption and volume by constituents in fetal sheep urine. Am J Physiol Regul Integr Comp Physiol 305:R506-R511 
Beall MH, Wang S, Yang B, Chaudhri N, Amidi F, Ross MG (2007) Placental and membrane aquaporin water channels: correlation with amniotic fluid volume and composition. Placenta. 28:421-428

Brace RA (1997) Physiology of amniotic fluid volume regulation. Clin Obstet Gynecol 40:280-289

Brace RA, Cheung CY (2014) Regulation of amniotic fluid volume: evolving concepts. Adv Exp Med Biol 814:49-68

Carbrey JM, Agre P (2009) Discovery of the aquaporins and development of the field. Handb Exp Pharmacol 190:3-28

Chou CL, Knepper MA, Hoek AN, Brown D, Yang B, Ma T, Verkman AS (1999) Reduced water permeability and altered ultrastructure in thin descending limb of Henle in aquaporin-1 null mice. J Clin Invest 103:491-496

Craciun MI, Domsa I (2017) Immunohistochemical diagnosis of Krukenberg tumors. Romanian J Morphol Embryol 58:845-849

Damiano AE (2011) Review: Water channel protein in the human placenta and fetal membranes. Placenta 32(Supp12):S207-S211

Ducza E, Csanyi A, Gaspar R (2017) Aquaporins during pregnancy: their function and significance. Int J Mol Sci 18

Gannon BJ, Warnes GM, Carati CJ, Verco CJ (2000) Aquaporin-1 expression in visceral smooth muscle cells of female rat reproductive tract. J Smooth Muscle Res 36:155-157

Gonen T, Walz T (2006) The structure of aquaporins. Q Rev Biophys 39: 361-396

Harman CR (2008) Amniotic fluid abnormalities. Semin Perinatol 32: 288-294

Hua Y, Jiang W, Zhang W, Shen Q, Chen M, Zhu X (2013) Expression and significance of aquaporins during pregnancy. Front Biosci (Landmark Ed). 18:1373-1383

Huang HF, He RH, Sun CC, Zhang Y, Meng QX, Ma YY (2006) Function of aquaporins in female and male reproductive systems. Hum Reprod Upadate 12:785-795

Ishibashi K, Kondo S, Hara S, Morishita Y (2011) The evolutionary aspects of aquaporin family. Am J Physiol Regul Integr Comp Physiol. 300:R566-R576

Jiang SS, Zhu XJ, Ding SD, Wang JJ, Jiang LL, Jiang WX, Zhu XQ (2012) Expression and localization of aquaporins 8 and 9 in term placenta with oligohydramnios. Reprod Sci 19:1276-1284

King LS, Nielsen S, Agre P (1996) Aquaporin-1 water channel protein in lung: ontogeny, steroid-induced expression, and distribution in rat. J Clin Invest 97:2183-2191

Ma T, Yang B, Gillespie A, Carlson EJ, Epstein CJ, Verkman AS (1998) Severely impaired urinary concentrating ability in transgenic mice lacking aquaporin-1 water channels. J Biol Chem 273:4296-4299

Madeira A, Moura TF, Soveral G (2015) Aquaglyceroporins: implications in adipose biology and obesity. Cell Mol Life Sci 72:759-771

Mann SE, Ricke EA, Yang BA, Verkman AS, Taylor RN (2002) Expression and localization of aquaporin 1 and 3 in human fetal membranes. Am J Obestet Gynecol 187:902-907

Mann SE, Ricke EA, Torres EA, Taylor RN (2005) A novel model of polyhydramnios: amniotic fluid volume is increased in aquaporin 1 knockout mice. Am J Obstet Gynecol 192:2041-2044 discussion 2044-2046

Mann SE, Dvorak N, Gilbert H, Taylor RN. (2006). Steady-state levels of aquaporin $1 \mathrm{mRNA}$ expression are increased in idiopathic polyhydramnios. Am J Obstet Gynecol.194:884-887

Mobasheri A, Marples D (2004) Expression of the AQP-1 water channel in normal human tissues: a semiquantitative study using tissue microarray technology. Am J Physiol Cell Physiol 286:C529-C537

Mukhopadhyay R, Bhattacharjee H, Rosen BP (2014) Aquaglyceroporins: generalized metalloid channels. Biochim Biophys Acta 1840:1583-1591

Phelan JP, Smith CV, Broussard P, Small M (1987) Amniotic fluid volume assessment with the four-quadrant technique at 36-42 weeks' gestation. J Reprod Med 32:540-542
Prat C, Blanchon L, Borel V, Gallot D, Herbet A, Bouvier D, Marceau G, Sapin V (2012) Ontogeny of aquaporins in human fetal membranes. Biol Reprod 86:48

Sha XY, Xiong ZF, Liu HS, Zheng Z, Ma TH (2011) Pregnant phenotype in aquaporin 8-deficient mice. Acta Pharmacol Sin 32:840-844

Sha XY, Liu HS, Ma TH (2015) Osmotic water permeability diversification in primary trophoblast cultures from aquaporin 1-deficient pregnant mice. J Obstet Gynaecol Res 41:1399-1405

Skowronski MT, Kwon TH, Nielsen S (2009) Immunolocalization of aquaporin 1,5 , and 9 in the female pig reproductive system. $\mathrm{J}$ Histochem Cytochem 57:61-67

Skowronski MT, Skowronska A, Rojek A, Oklinski MK, Nielsen S (2016) Prolonged starvation causes up-regulation of AQP1 in adipose tissue capillaries of AQP7 knock-out mice. Int J Mol Sci 17

Su W, Qiao Y, Yi F, Guan X, Zhang D, Zhang S, Hao F, Xiao Y, Zhang H, Guo L, Yang L, Feng X, Ma T (2010) Increased female fertility in aquaporin 8-deficient mice. IUBMB Life 62:852-857

Su W, Guan X, Zhang D, Sun M, Yang L, Yi F, Hao F, Feng X, Ma T (2013) Occurrence of multi-oocyte follicles in aquaporin 8-deficient mice. Reprod Biol Endocrinol 11:88

Sun XL, Zhang J, Fan Y, Ding JH, Sha JH, Hu G (2009) Aquaporin-4 deficiency induces subfertility in female mice. Fertil Steril 92:17361743

Tian Q, Stepaniants SB, Mao M, Weng L, Feetham MC, Doyle MJ, Yi EC, Dai H, Thorsson V, Eng J, Goodlett D, Berger JP, Gunter B, Linseley PS, Stoughton RB, Aebersold R, Collins SJ, Hanlon WA, Hood LE (2004) Integrated genomic and proteomic analyses of gene expression in mammalian cells. Mol Cell Proteomics 3:960-969

Verkman AS (1999) Lessons on renal physiology from transgenic mice lacking aquaporin water channels. J Am Soc Nephrol 10:1126-1135

Verkman AS (2011) Aquaporins at a glance. J Cell Sci 124:2107-2112

Verkman AS, Matthay MA, Song Y (2000) Aquaporin water channels and lung physiology. Am J Physiol Lung Cell Mol Physiol 278: L867-L879

Wang S, Kallichanda N, Song W, Ramirez BA, Ross MG (2001) Expression of aquaporin- 8 in human placenta and chorioamniotic membranes: evidence of molecular mechanism for intramembranous amniotic fluid resorption. Am J Obstet Gynecol 185:1226-1231

Wang S, Che J, Beall M, Zhou W, Ross MG (2004) Expression of aquaporin 9 in human chorioamniotic membranes and placenta. Am J Obstet Gynecol 191:2160-2167

Zhang J, Troendle J, Meikle S, Klebanoff MA, Rayburn WF (2004) Isolated oligohydramnios is not associated with adverse perinatal outcomes. BJOG. 111:220-225

Zhang D, Tan YJ, Qu F, Sheng JZ, Huang HF (2012a) Functions of water channels in male and female reproductive systems. Mol Asp Med 33:676-690

Zhang Y, Ding S, Shen Q, Wu J, Zhu X (2012b) The expression and regulation of aquaporins in placenta and fetal membranes. Front Biosci (Landmark Ed) 17:2371-2382

Zheng Z, Liu H, Beall M, Ma T, Hao R, Ross MG (2014) Role of aquaporin 1 in fetal fluid homeostasis. J Matern Fetal Neonatal Med 27:505-510

Zhu XQ, Jiang SS, Zhu XJ, Zou SW, Wang YH, Hu YC (2009) Expression of aquaporin 1 and aquaporin 3 in fetal membranes and placenta in human term pregnancies with oligohydramnios. Placenta. 30:670-676

Zhu X, Jiang S, Hu Y, Zheng X, Zou S, Wang Y (2010) The expression of aquaporin 8 and aquaporin 9 in fetal membranes and placenta in term pregnancies complicated by idiopathic polyhydramnios. Early Hum Dev 86:657-663

Publisher's note Springer Nature remains neutral with regard to jurisdictional claims in published maps and institutional affiliations. 